\title{
Host-Tumor Interaction
}

National Cancer Institute

\section{Source}

National Cancer Institute. Host-Tumor Interaction. NCI Thesaurus. Code C19365.

The efforts by the host to reject a tumor, and the mechanisms by a tumor to evade recognition by the immune system. 